\title{
A Patient with Acroangiodermatitis Without a History of Vascular Disease: A Case Report
}

\author{
Zhaleh Karimi-Moghaddam $^{\text {* }}$ (D), Fazlollah Ayatollahi ${ }^{2}$, Alireza Zeraatchi $^{3}$
}

1. Dept. Of Radiation Oncology, Vali-e-asr Hospital,School of Medicine, Zanjan University of Medical Sciences, Zanjan, Iran

2. Dept. Of Rheumatology, Vali-e-asr Hospital, School of Medicine, Zanjan University of Medical Sciences, Zanjan, Iran

3. Dept. Of Emergency Medicine, Vali-e-asr Hospital, School of Medicine, Zanjan University of Medical Sciences, Zanjan, Iran

\begin{tabular}{|c|c|}
\hline Article Info & ABSTRACT \\
\hline doi 10.30699/jambs.27.123.49 & \multirow{3}{*}{$\begin{array}{l}\text { Acroangiodermatitis (AAD), also known as Pseudo-Kaposi's sarcoma, is a rare } \\
\text { benign angioproliferative disease associated with chronic venous insufficiency (CVI) } \\
\text { or other vascular disorders. We present an } 81 \text {-year-old male with plaque-like } \\
\text { cutaneous lesions, which had progressive erythematous margins, severe pain, and } \\
\text { intense pruritus, as well as bilateral swollen and painful feet. It was around five } \\
\text { months that he had these problems. Based on the pathology of skin lesion biopsy } \\
\text { specimens and the immunohistochemical staining results (which indicated the } \\
\text { positivity of CD34), the diagnosis of pseudo-Kaposi's sarcoma was confirmed. }\end{array}$} \\
\hline $\begin{array}{l}\text { Received: 2019/02/01; } \\
\text { Accepted: 2019/04/28; } \\
\text { Published Online: } 10 \text { Jul 2019; }\end{array}$ & \\
\hline $\begin{array}{l}\text { Use your device to scan and read the } \\
\text { article online }\end{array}$ & \\
\hline \multirow{2}{*}{ 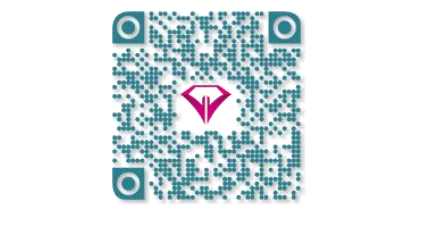 } & Keywords: Acroangiodermatitis, Angioproliferation, Pseudo-Kaposi's sarcoma \\
\hline & $\begin{array}{l}\text { Corresponding Information: } \\
\text { Zhaleh Karimi-Moghaddam, Dept. Of Radiation Oncology, Vali-e-asr Hospital, School of Medicine, Zanjan } \\
\text { University of Medical Sciences, Zanjan, Iran. } \\
\text { Email: zhkarimi@ zums.ac.ir }\end{array}$ \\
\hline $\begin{array}{l}\text { Copyright } \odot 2019 \text {, This is an } \\
\text { copy and redistribution of the }\end{array}$ & $\begin{array}{l}\text { en-access article distributed under the terms of the Creative Commons Attribution-noncommercial } 4.0 \text { International License which permits } \\
\text { ust in noncommercial usages with proper citation. }\end{array}$ \\
\hline
\end{tabular}

\section{Introduction}

Acroangiodermatitis (AAD), also known as PseudoKaposi's sarcoma, is a very rare benign vasoproliferative disease or disorder that affects the lower extremities (1-3). It appears to be a benign phenomenon related to severe chronic venous insufficiency (CVI), stasis, and arteriovenous malformations (AVMs) (e.g., KlippelTrenaunay syndrome [KTS], Prader-Labhart-Willi syndrome [PLWS], and Stewart-Bluefarb syndrome [SBS]) of the lower extremities $(3,4)$.

AAD was introduced for the first time by Mali et al. in 1965. Their study reported 18 cases with CVI in the lower extremities $(4,5)$. According to most case reports, AAD is frequently observed in the lower extremities of male adults with CVI $(5,6)$.

AAD presents with violaceous macules and patches that gradually develop into papules, nodules, or indurated plaques (often bilateral) and usually located on the extensor surfaces of the lower extremities. These lesions are benign, and they must be distinguished from other lesions, which are resulted from malignant conditions (such as Kaposi's sarcoma) and seen particularly in HIVpositive patients. It is, therefore, necessary to perform immunohistochemical tests to establish a differential diagnosis.

\section{Case Report}

The patient is an 81-year-old man that both sides of his feet were swollen and painful. He suffered from plaque-like cutaneous lesions, which had progressive erythematous margins, severe pain, and intense pruritus. He has had these problems for five months, which deteriorated during the last three months. The onset of the disease was from the left foot. The legs and knees were asymmetrically involved later. The patient had a history of taking aspirin $(80 \mathrm{mg}$ per day) because of coronary artery disease. He had neither a history of systematic diseases nor a positive family history. Further, physical examination revealed the one-plus pitting edema of the lower extremities, as well as numerous violaceous plaque-like lesions with irregular erythematous margins over the left and right feet and the left knee, which were located asymmetrically.

However, no clinical evidence of vascular disease or varicose veins was observed. The systemic examinations were normal. Routine tests, including the complete blood count with differential (CBC/Diff), liver and kidney function tests, and urinalysis (U/A), were also normal. The HIV antibody was negative, and the chest X-ray was normal. The other results were as follows: the erythrocyte sedimentation rate $(\mathrm{ESR})=34$ (normal <10); C-reactive protein $(\mathrm{CRP})=11.8($ normal $<6)$; and anti-double-stranded DNA $($ anti-dsDNA $)=1.8($ normal $<0.1)$. 


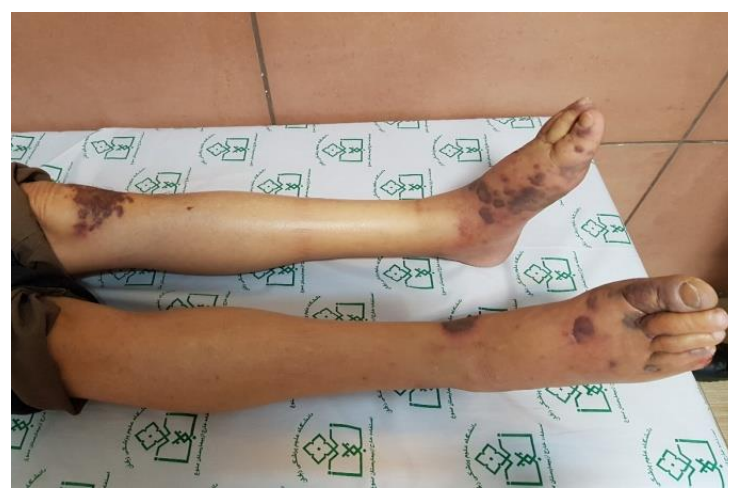

Figure 1. Numerous skin lesions in the two lower extremities.

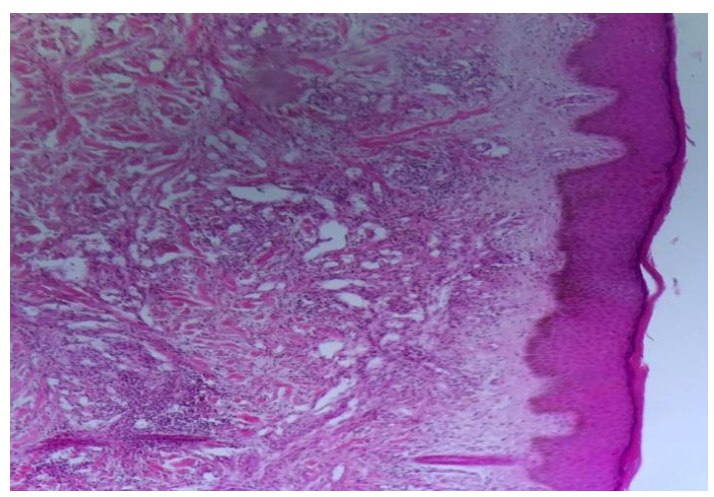

Figure 2. The skin tissue with nodular aggregates of blood vessels with perivascular inflammation. The small blood vessel wall has thickened and the vessels are lined by plump, atypical endothelial cells. The proliferation of perivascular fibroblasts and a moderate amount of hemosiderin deposits are observed around these vessels.

In addition, abdominal ultrasonography showed an infrarenal fusiform aneurysm in the abdominal aorta (44 $\mathrm{mm}$ in diameter) containing a mural thrombus. The arterial lumen diameter was $24 \mathrm{~mm}$. The color Doppler ultrasonography of the lower extremities showed that the blood flow was normal. The patient underwent a skin lesion biopsy. Altogether, the final diagnosis of AAD was confirmed based on his medical history, medical examination, and pathological findings.

\section{Discussion}

A differential diagnosis should be made to differentiate AAD from other conditions, such as Kaposi's sarcoma, vasculitis, actinic keratosis, stasis dermatitis, hemangiomas, lymphangiomas, and lymphangiosarcomas $(7,8)$. It must be remarked that, in rare cases, AAD develops in patients presenting no CVI or any underlying AVMs (7, 9-11). The pathological examination showed that there was intradermal capillary proliferation as small nodules with perivascular inflammation underlying the fibrous tissue. The mild infiltration of small lymphoid cells was observed around the nodules. The small blood vessel wall had thickened, and the vessels were lined with plump, atypical endothelial cells. Mild hemosiderin deposition was observed around the vessels. There was found no epidermotropism, panniculitis, or thrombosis.
Other vascular tumors, such as hemangioendothelioma, could be included in the differential diagnosis (6). The immunohistochemical stain CD34 is used to differentiate between Pseudo-Kaposi's sarcoma and Kaposi's sarcoma. In Pseudo-Kaposi's sarcoma, CD34 is positive in endothelial cells; however, it is negative in Kaposi's sarcoma (6). Pseudo-Kaposi's sarcoma and Kaposi's sarcoma have similar histopathological features; therefore, Pseudo-Kaposi's sarcoma is often clinically misdiagnosed as Kaposi's sarcoma (9).

Biopsy slides of the patient's lesions were double read, and Pseudo-Kaposi's sarcoma was diagnosed each time. Ultimately, applying immunohistochemistry (IHC), which showed the positivity of CD34, confirmed the diagnosis. In the lower limbs, AAD lesions appear mainly on the dorsal aspects of the feet, especially on the calves and ankles $(6,7)$.

In our patient, the lesions were on the soles, ankles, knees, and calves. The color Doppler ultrasonography is useful for determining the cause of lesions, including CVI. In this patient, the common femoral veins, superficial femoral veins, and popliteal veins had no thrombus, and the venous blood flow in both of the limbs was normal. Furthermore, the posterior tibial, anterior tibial, and peroneal veins had a normal venous blood flow. The treatment of this disease has been discussed in the available resources and depends on the underlying condition. In cases associated with CVI, compression bandaging and leg elevation could lead to improvement (6). In our patient, compression bandaging, leg elevation, and a 50-mg daily oral dose of dapsone for six months reduced skin lesions and pain.

\section{Conclusion}

It is necessary to differentiate Pseudo-Kaposi's sarcoma from Kaposi's sarcoma, because AAD is basically a benign, self-limiting condition; however, the latter is a malignant disease, which requires aggressive therapy, including chemotherapy, radiotherapy, and even grafting. The present research indicated that leg elevation, compression bandaging, and dapsone could improve cutaneous lesions associated with AAD.

\section{Acknowledgements}

The authors thank all those who helped them writing this paper.

\section{Conflict of Interest}

Authors declared no conflict of interests.

\section{References}

1. Singh SK . Manchanda KJIdoj. Acroangiodermatitis (Pseudo-Kaposi sarcoma). Indian Dermatol Online J.2014;5(3):323-2 [DOI:10.4103/2229-5178.137791]

2. Archie M, Khademi S, Aungst D, et al. A rare case of acroangiodermatitis associated with a congenital arteriovenous malformation (Stewart-Bluefarb Syndrome) 
in a young veteran: case report and review of the literature. Ann Vasc Surg. 2015;29(7):1448. e5-. e10. [DOI:10.1016/j.avsg.2015.03.055]

3. Palmer B, Xia Y, Cho S, Lewis FSJC. Acroangiodermatitis secondary to chronic venous insufficiency. Cutis . 2010;86(5):239-40.

4. Mehta AA, Pereira RR, Nayak CS, Dhurat R. Acroangiodermatitis of mali: A rare vascular phenomenon. Indian J Dermatol Venereol Leprol 2010;76(5):553-6 [DOI:10.4103/0378-6323.69090]

5. Marshall ME, Hatfield ST, Hatfield DRJAod. Arteriovenous malformation simulating Kaposi's sarcoma:(pseudo-Kaposi's sarcoma). Arch Dermatol. 1985;121(1):99-101. [DOI:10.1001/archderm.121.1.99]

6. Hung NA, Strack M, Rij AV, North CJ, Blennerhassett JB. Spontaneous acroangiodermatitis in a young woman. Dermatol Online J.2004;10(2):8
7. Rao B, Unis M, Poulos E. Acroangiodermatitis: a study of ten cases. Int J Dermatol. 1994;33(3):179-83. DOI:10.1111/j.1365-4362.1994.tb04944.x

8. Goorney B, Newsham J, Fitzgerald D, Motta LJIjo S. Acroangiodermatitis mimicking Kaposi's sarcoma in an HIV-positive man. Int J STD AIDS. 2018;29(7):729-31. [DOI:10.1177/0956462417750709]

9. Coban I, Kokenek-Unal TD, Alper M. Spontaneous acroangiodermatitis. Indian J Dermatol . 2015 2019;60:26871. http://doi.org/10.4103/0019-5154.156376

10. Sinha L, Padmavathi, Anantharaj J. Acroangiodermatitis of mali. J Evolution Med Dent Sci. 2016; 5(18):911-913. DOI: 10.14260/jemds/2016/211

11. Horiguchi Y, Takahashi K, Tanizaki H, Miyachi Y. Case of bilateral acroangiodermatitis due to symmetrical arteriovenous fistulas of the soles. J Dermatol. 2015;42(10):989-91. [DOI:10.1111/1346-8138.12934]

\section{How to Cite This Article:}

Karimi-Moghaddam Z, Ayatollahi F, Zeraatchi A. A Patient with Acroangiodermatitis Without a History of Vascular Disease: A Case Report. J Adv Med Biomed Res. 2019; 27 (123) :49-51

\section{Download citation: \\ $\underline{\text { BibTeX }}|\underline{\text { RIS }}| \underline{\text { EndNote }}|\underline{\text { Medlars }}| \underline{\text { ProCite }}|\underline{\text { Reference Manager }}| \underline{\text { RefWorks }}$}

\section{Send citation to:}

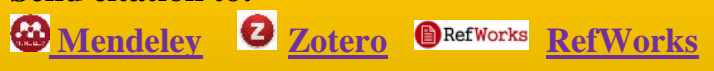

